\title{
On the Pharmacotherapy of Sleep Bruxism: Placebo-Controlled Polysomnographic and Psychometric Studies with Clonazepam
}

\author{
Alexander Saletu $^{\mathrm{a}}$ Silvia Parapatics ${ }^{\mathrm{b}-\mathrm{d}}$ Bernd Saletu $^{\mathrm{b}, \mathrm{d}}$ \\ Peter Anderer $^{b}$ Wolfgang Prause ${ }^{b}$ Hanna Putz ${ }^{d}$ Josef Adelbauer ${ }^{d}$ \\ Gerda Maria Saletu-Zyhlarz ${ }^{b, d}$ \\ Departments of ${ }^{\mathrm{a}}$ Dental Medicine, ${ }^{\mathrm{b}}$ Psychiatry and ${ }^{\mathrm{c}}$ Medical Cybernetics and Artificial Intelligence, \\ Medical University of Vienna, and ${ }^{\mathrm{d}}$ Rudolfinerhaus, Vienna, Austria
}

\section{Key Words}

Sleep bruxism · Pharmacotherapy · Clonazepam •

Polysomnography · Awakening quality •

Thymopsyche $\cdot$ Noopsyche $\cdot$ Periodic limb

movements $\cdot$ Respiratory variables · Arousals

\begin{abstract}
Objectives: Sleep bruxism (SB) is a parasomnia defined as a stereotyped movement disorder characterized by grinding or clenching of the teeth during sleep. Pathophysiologically, SB is the result of biological and psychosocial influences. Treatment comprises behavioral, orthodontic and pharmacological interventions. While benzodiazepines and muscle relaxants have been reported by clinicians to reduce bruxism-related motor activity, placebo-controlled studies are lacking. Thus, the aim of the present study was to investigate the acute effects of clonazepam (Rivotril ${ }^{\circledR}$ ) as compared with placebo, utilizing polysomnography and psychometry. Method: Ten drugfree outpatients ( 6 females, 4 males), aged $46.5 \pm 13.1$ years, suffering from SB (ICD-10: F45.8; ICSD: 306.8) and having been treated by bite splints were included in the trial. Comorbidity was high: 7 patients presented nonorganic insomnia related to adjustment or anxiety disorders (5 patients) or depression (2 patients); all patients had a concomitant movement disorder $(6$ restless legs syndrome, 4 periodic leg movement disorder). After one ad-
\end{abstract}

(C) 2005 S. Karger AG, Basel 0302-282X/05/0514-0214\$22.00/0

Fax +4161306 1234 E-Mail karger@karger.ch www.karger.com www.karger.com/nps aptation night, patients received placebo and $1 \mathrm{mg}$ clonazepam 1/2 hour before lights out in a single-blind, nonrandomized study design. Objective sleep quality was determined by polysomnography, subjective sleep and awakening quality by rating scales, objective awakening quality by psychometric tests. Clinical evaluation was based on the Pittsburgh Sleep Quality Index (PSQI), the Zung Depression (SDS) and Anxiety (SAS) Scales, the Quality of Life Index, the Epworth Sleepiness Scale and the International Restless Legs Syndrome Study Group (IRLSSG) Scale. Results: On admission, SB patients exhibited deteriorated PSQI, SAS, SDS and IRLSSG measures. As compared with placebo, $1 \mathrm{mg}$ clonazepam significantly improved the mean bruxism index from 9.3 to $6.3 / \mathrm{h}$ of sleep. Furthermore, it significantly improved the total sleep period, total sleep time, sleep efficiency, sleep latency and time awake during the total sleep period, and increased stage 2 sleep and movement time. Periodic leg movements decreased significantly, while the apnea index and apnea-hypopnea index increased marginally, but remained within normal limits. Subjective sleep quality improved as well, while in mood, performance and psychophysiology no changes were observed. Conclusion: Acute clonazepam therapy significantly improved not only the bruxism index but also objective and subjective sleep quality, with unchanged mood, performance and psychophysiological measures upon awakening, suggesting good tolerability of the drug.

Copyright $(2005$ S. Karger AG, Basel

Univ. Ass. DDr. Alexander Saletu, MD, Clinic of Dentistry

Department of Periodontology, Medical University of Vienna

Währinger Strasse 25a, AT-1090 Vienna (Austria)

Tel. +431 427767211, Fax +431427767 205

E-Mail alexander.saletu@meduniwien.ac.at 


\section{Introduction}

According to the International Classification of Sleep Disorders (ICSD), sleep bruxism (SB) is a parasomnia (i.e. an undesirable physical phenomenon occurring during sleep) characterized by a stereotyped movement disorder consisting of grinding or clenching of the teeth during sleep [1]. In the International Classification of Diseases, 10th revision (ICD-10), by the WHO [2], bruxism is listed in chapter F 'Mental and Behavioral Disorders' under F45.8 'Other Somatoform Disorders'. This suggests that in the pathogenesis of SB, stress and psychosocial variables play a role, which has indeed been postulated by a number of authors [3-8], although another study found no relationship between stress in the waking state and electromyogram (EMG) changes in sleep [9]. There is, however, a consensus that SB patients have an anxious personality and are focused on successful performance $[4,6-8,10-12]$. Other exogenous and peripheral pathogenetic factors include environmental influences, occlusion, some kinds of medication ( $L$-dopa, neuroleptics, amphetamines, selective serotonin reuptake inhibitors) and substance abuse (e.g. cocaine, alcohol, smoking) $[13,14]$. Endogenous factors include personality (e.g. anxious), genetic factors, neurochemicals (e.g. dopamine, serotonin), neurological disorders (e.g. Parkinson's disease, Meigs syndrome, oral tardive dyskinesia, REM behavior disorder, olivopontocerebellar atrophy and cerebellar hemorrhage), psychiatric disorders (e.g. anxiety, adjustment and affective disorder, dementia, mental retardation, tics) and sleep disorders [e.g. periodic leg movements in sleep (PLMS), apnea, REM behavior disorder]. Macaluso et al. [15] and Kato et al. [16] suggested that SB is a sequel of microarousals during sleep (sudden brain and cardiac activation). If REM bruxism is associated with neuropsychiatric disorders or substance use, it is referred to as secondary bruxism [14].

The prevalence of sleep bruxism is approximately $8 \%$ [17-20]. That of wake bruxism, a condition usually characterized by jaw clenching and only rarely by tooth gnashing and/or grinding, is about $20 \%$. With increasing age, SB decreases, with a prevalence rate of $14 \%$ in children, $8 \%$ in adults and $3 \%$ in patients over 60 years of age [ 19 , 21].

The sequelae of SB include tooth destruction (fig. 1), temporo-mandibular dysfunction (e.g. jaw pain or movement limitation), rarely cephalgia, and last but not least sleep disturbances of the bed partner due to the grinding sounds $[14,22]$.

Sleep Bruxism: Sleep Laboratory Studies with Clonazepam
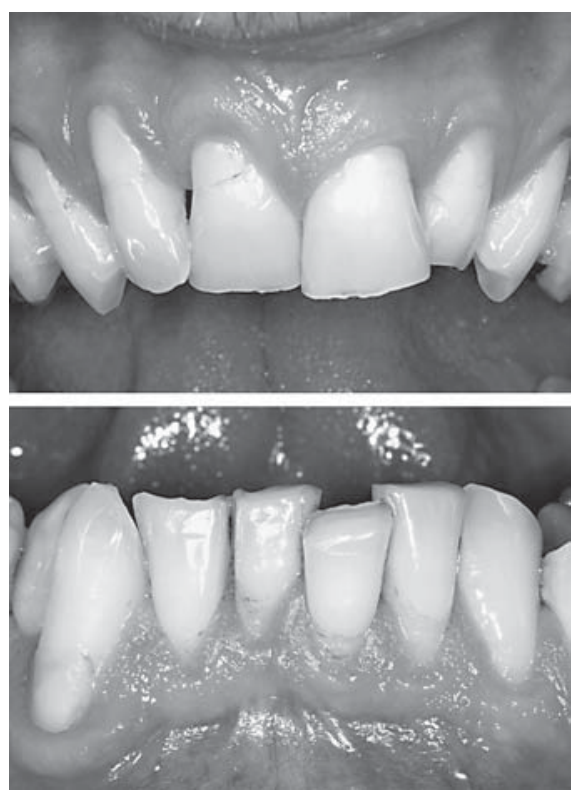

Fig. 1. Tooth wear as a consequence of SB.

Diagnostic evaluation comprises clinical diagnosis, ambulatory monitoring, sleep laboratory investigations and others [14]. The clinical approach is based on the patient's history (e.g. reports of tooth grinding, jaw muscle tightness, discomfort, or pain) and orofacial examination. According to Johansson et al. [23], tooth enamel or crown wear with the presence of facets (shiny spots) may be scored, distinguishing three classes: class I - tooth enamel or crown wear with the presence of facets (polishlike) or fillings with shiny spots; class II - loss of enamel with dentine exposure and slight reduction of crown height or chipped incisal ridge or cuspids; class III - extensive dentine wear $\left(>2 \mathrm{~mm}^{2}\right)$ with loss of crown height $(>50 \%)$ and flattening of cusps (fig. 1).

Ambulatory monitoring includes audio/video home recordings to estimate sound frequency and jaw displacement as well as ambulatory EMG recordings (e.g. masseteric EMG monitoring during sleep) [14]. Lately, also full ambulatory multichannel recorders have been developed. However, only full polysomnography in the sleep laboratory makes it possible to recognize SB motor activity that may otherwise be confounded with jaw activity during sleep such as swallowing, coughing, sleep talking, sighing, grunting, yawning, smiling or myoclonus [14, 24, 25].

Criteria suggested for the diagnosis of SB based on sleep laboratory recordings [24] are as follows: mean EMG potentials are larger than $20 \%$ of the maximum voluntary clench while awake. SB episode types can be

Neuropsychobiology 2005;51:214-225 


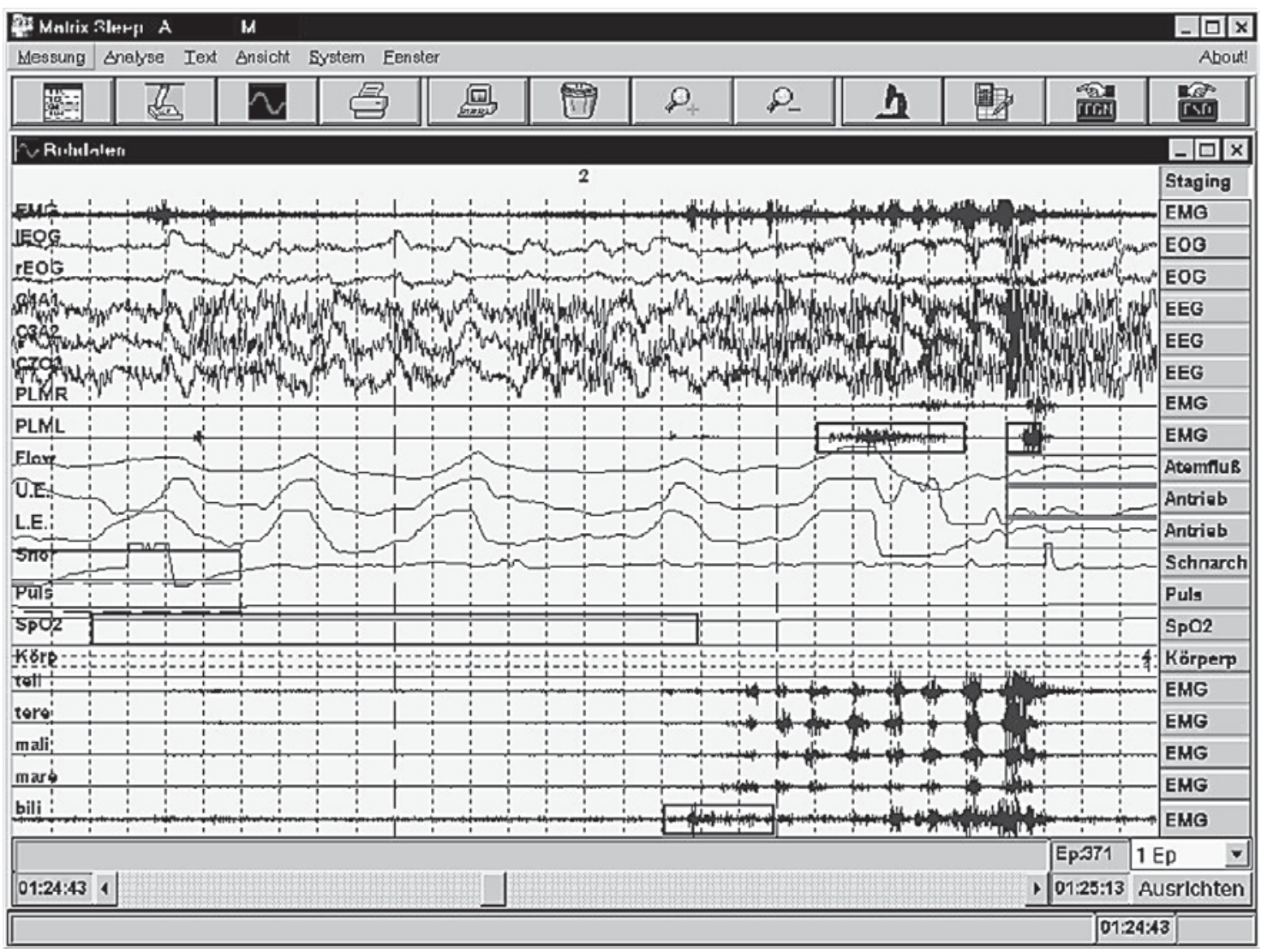

Fig. 2. Example of a 30-second polysomnogram demonstrating one rhythmical SB episode. The 20 polygraphic traces demonstrate from top to bottom: submental electromyogram (EMG), left and right electrooculogram (EOG), right (C4) and left (C3) central and vertex $(\mathrm{CZ}) \mathrm{EEG}$, right and left PLM recordings from the respective anterior tibial muscle, airflow and upper and lower respiratory efforts, snoring, pulse rate, oxygen saturation $\left(\mathrm{Sp} \mathrm{O}_{2}\right)$ and body po-

subdivided into phasic (rhythmical), tonic (sustained) and mixed ones. Phasic episodes are characterized by more than 3 EMG bursts, separated by 2 interburst pauses, in the masseter or temporalis muscle lasting $>0.25 \mathrm{~s}$ and $<2.0 \mathrm{~s}$ (fig. 2). In tonic episodes, there is 1 EMG burst lasting $>2 \mathrm{~s}$. Mixed episodes have both phasic and tonic components. The minimum acquisition frequency is $128 \mathrm{~Hz}$, the diagnostic cutoff criteria for research purposes are as follows: sensitivity $>72 \%$; specificity $>94 \%$, bruxism episodes per hour $>4$, bruxism bursts per hour $>25$, minimum episodes with grinding 1 per sleep period.

Over $88 \%$ of SB episodes are phasic or mixed. Sixty to eighty percent of jaw muscle activity in SB occurs during light sleep, at a mean frequency of 5.4-5.8 episodes per hour of sleep $[15,24,26]$. sition, as well as left and right temporalis and masseter muscles and finally left biventer muscle. Note the 10 phasic rhythmical bursts demonstrating a co-contraction between the closer (teli = left temporalis, tere $=$ right temporalis, mali $=$ left masseter, mare $=$ right masseter muscle) and the submental opener muscles (EMG and bi $=$ biventer muscle). Note further concomitant PLMs.

It is of interest that rhythmic masticatory muscle activity during sleep also occurs in about $60 \%$ of normal subjects, though with a frequency of 1.8 episodes per hour of sleep [26, 27]. Lavigne et al. [26], however, pointed out that in SB the frequency of rhythmic masticatory muscle activity is three times higher than in normal subjects, the muscle contractions are of a higher amplitude and tooth grinding sounds are present.

Treatment consists of psychological, somatic and pharmacological strategies, which are also known to be the three pillars in the therapy of sleep disorders in general [28]. Psychological interventions include explaining SB to the patient and providing sleep hygiene instructions (e.g. the 10 commandments for good sleep [28]). No persistent effects have been obtained with relaxation strategies $[3,29,30]$, though some patients report an increase 
Table 1. Demographic data and ICD-10 diagnoses in 10 sleep bruxers

\begin{tabular}{rllllllll}
\hline $\begin{array}{l}\text { Patient } \\
\text { No. }\end{array}$ & Lab No. & Initials & Sex & $\begin{array}{l}\text { Age } \\
\text { years }\end{array}$ & $\begin{array}{l}\text { Weight } \\
\mathrm{kg}\end{array}$ & Bruxism & $\begin{array}{l}\text { Movement } \\
\text { disorder }\end{array}$ & Other diagnoses \\
\hline 1 & 573 & M.S. & F & 62 & 78 & F45.8 & G25.8 & \\
2 & 647 & G.H. & F & 55 & 72 & F45.8 & G25.8 & F51.0, F33.10, F43.22, F51.5 \\
3 & 661 & K.K. & F & 40 & 52 & F45.8 & G25.8 & F51.0, F43.22, F51.5 \\
4 & 725 & H.V. & F & 41 & 83 & F45.8 & G 25.8 & F51.0, F43.22, F51.5, F34.0, F40.01 \\
5 & 795 & P.N. & M & 28 & 75 & F45.8 & G25.8 & F51.0, F41.1, R06.5 \\
6 & 812 & T.P. & M & 34 & 80 & F45.8 & G25.3 & F51.0, F41.1 \\
7 & 846 & H.S. & F & 64 & 86 & F45.8 & G25.3 & F51.0, F31.8 \\
8 & 857 & M.A. & F & 49 & 82 & F45.8 & G25.8 & R06.5 \\
9 & 862 & A.D. & M & 59 & 78 & F45.8 & G25.3 & F51.0, F43.2 \\
10 & 668 & S.S. & M & 33 & 59 & F45.8 & G25.3 & F51.0, F43.21 \\
\hline
\end{tabular}

in well-being. Clarke and Reynolds [31] conducted a pilot study on hypnotherapy in bruxism and reported a reduction of both grinding frequency and EMG activity. Also, biofeedback has been used in the context of SB [32, 33].

Orodental treatment, such as mouth guards or stabilization bite splints, may protect orofacial structures from damage, but studies concerning the effect of splints on SB EMG-related levels show equivocal results. Pierce and Gale [29] and Solberg et al. [34] described an improvement, Clark et al. [35] and Okeson [36] found an increase in muscle activity in $20 \%$ of hard splint users and $50 \%$ of soft splint users, while others reported no change [37, 38]. Dao and Lavigne [39] therefore regarded splints as 'crutches' or 'bumpers' preventing tissue damage rather than showing an effect on SB, which may be the reason for low compliance (fewer than $20 \%$ of patients use their splints after 1 year). Tooth equilibration for reduction of occlusal interference was suggested by Yustin et al. [40] and Ramfjord and Mich [41], but its efficacy is controversial [42-44].

Comparing an occlusal splint with a palatal control device, Dube et al. [45] found a significant reduction $(41 \%)$ in the number of SB episodes per hour with both devices. In a case report study during continuous positive airway pressure titration in a patient with obstructive sleep apnea, Oksenberg and Arons [46] reported an elimination of most breathing abnormalities and a complete eradication of the tooth grinding events.

Pharmacotherapy of SB is also controversial as reports on dopaminergic, serotoninergic and adrenergic drugs describe a suppression or exacerbation of bruxism activity in humans and animals [47]. More controlled research is needed in this field.
As in a preceding pilot trial involving the dopamine agonist ropinirole, the benzodiazepine clonazepam and GABA hydroxybutyrate, clonazepam had shown the most promising results [48], the present placebo-controlled sleep laboratory study was carried out to investigate the acute effect of clonazepam on SB as well as on objective and subjective sleep and awakening quality of bruxers.

\section{Methods}

\section{Patients}

Ten drug-free patients ( 6 females, 4 males), aged $46.5 \pm 13.1$ years, suffering from SB (ICD-10: F45.8) participated in the study. They all fulfilled the inclusion criteria of SB according to the ICSD (306.8): (a) the patient has had a complaint of tooth grinding or tooth clenching; (b) one or more of the following occurred: (1) abnormal wear of teeth (all patients had already received splints by their dentists), (2) sounds associated with bruxism, (3) jaw muscle discomfort; (c) polysomnography demonstrates both (1) jaw muscle activity during sleep, and (2) absence of associated epileptic activity.

Comorbidity was high (table 1). All bruxers were suffering from movement disorders; 6 from restless legs syndrome (RLS) and 4 from PLMS. Moreover, 7 had nonorganic insomnia, which in 2 cases was related to affective disorders, and in 5 to neurotic, stressrelated and somatoform disorders. The study was performed in accordance with the rules and regulations for the conduct of clinical trials stated in the Declaration of Helsinki, as revised by the World Medical Assembly in Somerset West. Informed consent was obtained.

\section{Study Design}

In the single-blind, placebo-controlled, nonrandomized, crossover study, patients were investigated for three consecutive nights:

(1) Predrug night

(2) Placebo night

(3) Clonazepam $1 \mathrm{mg}$ night. 


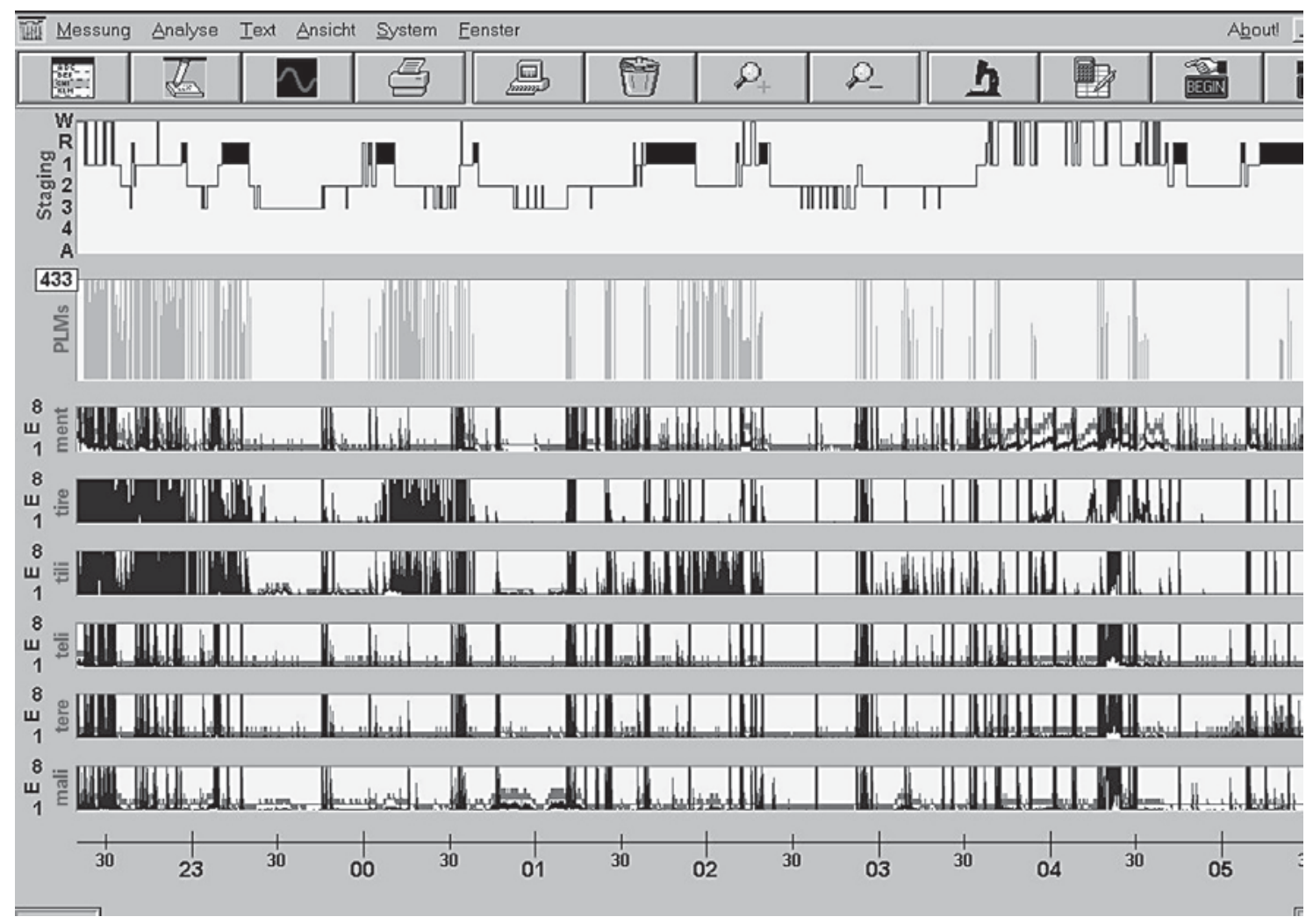

Fig. 3. Example of a computer printout of a female sleep bruxer. Below the sleep profile, the following measures are shown over time in descending order: PLMs, submental EMG, right and left anterior tibial muscle activity (tire, tili), left and right temporalis muscle activity (teli, tere) and left masseter muscle activity (mali). Note the partly independent, partly synchronous activities.

At the time of admission, the patients were required to have been free of psychopharmacological treatment for 5 times the halflife of the psychopharmacological agent given last.

The concomitant use of sedatives, propranolol, $\alpha$-methyldopa, antidepressants, tranquilizers, antihistamines, amphetamine-containing compounds, narcotic analgesics, anticholinergics or alcohol was prohibited during the study. Aspirin or acetaminophen could be taken, but the patients were instructed to refrain from doing so after 5.00 p.m. during the study.

In addition, meals, coffee, tea, Coca Cola or other caffeine-containing beverages were to be avoided within $8 \mathrm{~h}$ of retiring. No other medication was allowed after the study treatment had been taken at bedtime. The patients were required not to nap during the day or evening for the duration of the study.

\section{Measures}

Clinical Evaluation

The following clinical rating scales were completed on admission:

Pittsburgh Sleep Quality Index [49], Zung Self-Rating Scale for Depression (SDS) [50], Zung Self-Rating Scale for Anxiety (SAS) [51], Epworth Sleepiness Scale [52], International Restless Legs Syndrome Study Group Rating Scale (IRLSSG) [53], and Quality of Life Index according to Mezzich and Cohen [see ref. 54-56].
Evaluation of Objective Sleep Quality

Polysomnographic all-night recordings were obtained between approximately 10.30 p.m. (lights out) and 6.00 a.m. (buzzer or alarm clock). Thus, time in bed (TIB) was fixed to $7.5 \mathrm{~h}$. Data were recorded by means of a 16-channel polygraph (Jaeger Sleep Lab 1000P) including 3 EEG channels (C4-A1, CZ-O2 and C3-A2) according to the $10 / 20$ system, 2 electrooculogram channels (left/ right), submental EMG and tibialis anterior EMG from both legs, nasal and oral airflow, movement of the chest and abdomen, snoring, transcutaneous oxygen saturation and pulse rate (Criticare Pulse Oxymeter 504) (fig. 2).

For evaluation of SB, the jaw masseter, temporalis and biventer muscles were recorded, analyzed according to the criteria of Lavigne et al. [24] and plotted together with the sleep profile and PLM measures over the $7.5 \mathrm{~h}$ TIB (fig. 3).

Respiratory events such as apneas (more than $10 \mathrm{~s}$ without nasal or oral flow and cessation or cancellation of movements of chest and abdomen), hypopneas (more than 50\% reduction in the respiratory amplitude for at least $10 \mathrm{~s}$ ), snoring events, desaturation events (reduction of the start oxygen saturation value by 4\%), minimum $\mathrm{O}_{2}$ values and average low oxygen saturation were determined automatically by means of SleepLab 1000 P software.

PLM parameters were scored visually based on the recommendation of the Sleep Disorders Atlas Task Force of the American 
Sleep Disorders Association [57] with the following criteria: (1) an EMG burst length between 0.5 and $5.0 \mathrm{~s}$; (2) a movement amplitude $>25 \%$ of a calibration movement; (3) an interval of 5-90 s between movements; (4) a minimum number of 4 consecutive movements required for a group of movements to be scored as PLM. PLM indices were subdivided into PLM/h of TIB, PLM/h of total sleep time (TST), PLM arousals/h of sleep, PLM/h of REM, PLM/h of non-REM, and PLM/h of time awake.

Arousals were subjected to a computer-assisted classification according to the following rules: minimum frequency change required $2.5 \mathrm{~Hz}$; minimum frequency level $6 \mathrm{~Hz}$; required amplitude increase $30 \%$; minimal duration $3 \mathrm{~s}$; maximal duration $15 \mathrm{~s}$; EMG ratio for REM 2.0. Subsequently, arousals were visually scored on the basis of the EEG arousal scoring rules published by the Sleep Disorders Atlas Task Force of the American Sleep Disorders Association [58].

For sleep staging, 30-second epochs were visually scored according to the criteria of Rechtschaffen and Kales [59].

TST is the amount of actual sleep time in the total sleep period (TSP). TSP is the period of time measured from sleep onset until the final awakening. In addition to TST, TSP includes time awake and movement time. The number of awakenings refers to arousals to wakefulness during the TSP. The sleep efficiency index is the proportion of sleep in the recorded period, and it is calculated by dividing TST by the TIB, multiplied by 100 . Sleep stages (S) 1-4 and REM are expressed in minutes and in percentages of the TST. Latency to S1, S2, S3 and S4 defines the period of time measured from lights out to the appearance of S1, S2, S3 and S4, respectively. REM latency is defined as time from the first epoch of $\mathrm{S} 2$ (followed by $>8 \mathrm{~min}$ sleep in the next $10 \mathrm{~min}$ ) to the first REM period of at least $3 \mathrm{~min}$. Wake before buzzer is the time spent awake from the final awakening until the buzzer. Stage shifts refer to the number of shifts from one stage to another during TIB.

Subjective Sleep and Awakening Quality

After awakening, the patients completed the Self-Rating Scale for Sleep and Awakening Quality [28, 60, 61], including a 100-mm Visual Analog Scale (VAS) for RLS symptomatology. The VAS consisted of a line of $100 \mathrm{~mm}$, on which the patient had to mark his present condition, distinguishing between 'no symptoms at all' (left end) and 'most severe symptoms' (right end).

Thymopsychic variables included subjective well-being in the evening and morning, based on the 'Befindlichkeits-Skala' (emotional well-being and mood scale) by Von Zerssen et al. [62], as well as drive, mood, affectivity and drowsiness in the morning, measured by means of 100-mm VAS.

Objective Awakening Quality (Psychometry)

Morning mental performance tests included the Alphabetical Cancellation Test (Alphabetischer Durchstreichtest) [63] for quantification of attention (total score), concentration (errors in percentage of the total score) and attention variability (difference between extreme scores), the Numerical Memory Test as well as the Fine Motor Activity Test (right and left hand) [63] for the evaluation of changes in psychomotor activity and drive. Reaction time, reaction time variability $(\mathrm{ms})$ and errors of omission and commission were determined by the Viennese computer-assisted reaction time apparatus.

Sleep Bruxism: Sleep Laboratory Studies with Clonazepam
Psychophysiological Investigations

These included muscular strength of the right and left hand as well as of the right and left index finger and thumb, evaluated by means of a vigorimeter $\left(\mathrm{kp} / \mathrm{cm}^{2}\right)$ [64]. Evening and morning pulse rates as well as systolic and diastolic blood pressures were also recorded.

Biometric Planning and Statistics

The sample size was based on the meta-analysis study on sleep in psychiatric disorders by Benca et al. [65] as well as on our previous papers on neuropsychiatric disorders [66-73].

Statistical analysis was based on the concept of descriptive data analysis, as proposed by Abt [74] and Ferber et al. [75] for controlled clinical trials, which allows one confirmatory statement on a preselected variable based on previous findings [70].

The preselected null hypothesis was that there were no differences between clonazepam $1 \mathrm{mg}$ and placebo in terms of the primary target variable - the bruxism index (episodes/h of sleep) (maximum error probability $\alpha=0.05$ ).

Normal distribution was tested by means of the 1-sample Kolmogorov-Smirnov test. If in no cases the null hypothesis of normal distribution was rejected at $\alpha=0.10$, a two-way ANOVA was used within the group. In the case of a violation of the assumption of normal distribution, a Wilcoxon test was used for within-group comparisons.

All other effects were tested descriptively. The null hypotheses were: there are no differences between clonazepam and placebo nights (error probability $=0.05$ ).

\section{Results}

\section{Description of the Patients}

Clinical evaluation of the patients on admission demonstrated an increased Pittsburgh Sleep Quality Index of $10.8 \pm 4.0$ as compared with normals $(2.7 \pm 1.7)$, which reflects a disorder of sleep initiation and maintenance in the last 4 weeks. The SDS showed a mean value of $40.6 \pm$ 7.9 , suggesting a slight depressive syndrome as compared with normals (26 \pm 4$)$; the SAS yielded a mean value of $35.5 \pm 8.0$, indicating a slight anxiety syndrome as compared with normals $(26 \pm 3.5)$. The Epworth Sleepiness Scale demonstrated a mean value of $9.9 \pm 7.0$, suggesting only marginally increased daytime sleepiness as compared with controls $(5.9 \pm 2.2)$. The mean value of the IRLSSG rating scale was $6.6 \pm 7.6$, reflecting a slight increase in RLS symptomatology as compared with normals (0). Finally, the Quality of Life Index according to Mezzich and Cohen [see ref. 54-56] was slightly deteriorated with 7.5 \pm 10.9 as compared with normative data of $8.5 \pm 0.7$.

\section{Objective Sleep Quality - Sleep Initiation and Maintenance \\ SB patients showed a first-night effect in regard to la- tency to $\mathrm{S} 4$ and the number of nocturnal awakenings as}


Table 2. Acute effects of $1 \mathrm{mg}$ clonazepam on sleep initiation and maintenance in sleep bruxers $(\mathrm{n}=10)$ as compared with placebo

\begin{tabular}{|c|c|c|c|c|}
\hline Variables & A & $\mathrm{P}$ & $\mathrm{C}$ & $\begin{array}{l}\text { Internight } \\
\text { differences } \\
\text { (Wilcoxon test) }\end{array}$ \\
\hline Latency to $\mathrm{S} 1, \min \downarrow$ & $39.2 \pm 26.5$ & $15.7 \pm 11.9$ & $7.2 \pm 5.9$ & $\mathrm{C}: \mathrm{P}^{*}$ \\
\hline Latency to $S 2, \min \downarrow$ & $73.2 \pm 87.3$ & $20.7 \pm 12.9$ & $11.4 \pm 6.4$ & $\mathrm{C}: \mathrm{P}^{*}$ \\
\hline Latency to $\mathrm{S} 3, \min \downarrow$ & $118.8 \pm 128.4$ & $40.4 \pm 19.1$ & $37.8 \pm 19.0$ & \\
\hline Latency to $\mathrm{S} 4$, $\min \downarrow$ & $235.8 \pm 184.4$ & $51.3 \pm 19.6$ & $67.8 \pm 46.4$ & $\mathrm{~A}: \mathrm{P}^{*}$ \\
\hline Latency to REM, min $\downarrow$ & $115.8 \pm 58.5$ & $101.1 \pm 35.3$ & $104.1 \pm 62.9$ & \\
\hline Wake within TSP, min $\downarrow$ & $68.7 \pm 39.1$ & $58.0 \pm 48.7$ & $23.0 \pm 26.6$ & $\mathrm{C}: \mathrm{P}^{*}$ \\
\hline Wake before buzzer, min $\downarrow$ & $5.5 \pm 13.9$ & $3.9 \pm 6.8$ & $0.2 \pm 0.6$ & \\
\hline Awakenings, $\mathrm{n} \downarrow$ & $20.3 \pm 5.2$ & $14.8 \pm 4.7$ & $10.7 \pm 6.0$ & $\mathrm{~A}: \mathrm{P}^{*}$ \\
\hline $\mathrm{TSP}, \min \uparrow$ & $429.3 \pm 28.6$ & $430.5 \pm 14.0$ & $445.1 \pm 10.0$ & $\mathrm{C}: \mathrm{P}^{*}$ \\
\hline $\mathrm{TST}, \min \uparrow$ & $359.5 \pm 54.8$ & $371.9 \pm 49.2$ & $420.7 \pm 26.7$ & $\mathrm{C}: \mathrm{P}^{*}$ \\
\hline Sleep efficiency, $\% \uparrow$ & $80.0 \pm 12.1$ & $82.6 \pm 11.1$ & $93.0 \pm 5.7$ & $\mathrm{C}: \mathrm{P}^{*}$ \\
\hline
\end{tabular}

$\mathrm{A}=$ Predrug night; $\mathrm{P}=$ placebo night; $\mathrm{C}=$ clonazepam $1 \mathrm{mg}$ night; $\uparrow \downarrow=$ direction of improvement. $* \mathrm{p}<0.05$.

Table 3. Acute effects of $1 \mathrm{mg}$ clonazepam on sleep architecture in sleep bruxers $(\mathrm{n}=10)$ as compared with placebo

\begin{tabular}{|c|c|c|c|c|c|}
\hline \multicolumn{2}{|c|}{ Variables } & A & $\mathrm{P}$ & $\mathrm{C}$ & $\begin{array}{l}\text { Internight } \\
\text { differences } \\
\text { (Wilcoxon test) }\end{array}$ \\
\hline \multirow[t]{2}{*}{ S1 } & $\%$ & $10.6 \pm 4.8$ & $11.0 \pm 5.5$ & $10.2 \pm 4.9$ & \\
\hline & $\min$ & $38.8 \pm 20.2$ & $41.4 \pm 23.1$ & $42.7 \pm 20.6$ & \\
\hline \multirow[t]{2}{*}{ S2 } & $\%$ & $47.1 \pm 6.4$ & $50.5 \pm 6.2$ & $52.6 \pm 6.2$ & $\mathrm{C}: \mathrm{P}^{* *}$ \\
\hline & $\min$ & $169.4 \pm 36.5$ & $188.1 \pm 36.1$ & $221.8 \pm 33.9$ & $\mathrm{~A}: \mathrm{P}^{*}$ \\
\hline \multirow[t]{2}{*}{$\mathrm{S} 3$} & $\%$ & $13.1 \pm 5.2$ & $9.5 \pm 3.9$ & $9.5 \pm 2.2$ & \\
\hline & $\min$ & $46.6 \pm 18.8$ & $34.3 \pm 12.4$ & $40.2 \pm 9.9$ & \\
\hline \multirow[t]{2}{*}{ S4 } & $\%$ & $9.2 \pm 5.3$ & $10.4 \pm 5.2$ & $9.0 \pm 4.5$ & \\
\hline & $\min$ & $32.0 \pm 15.3$ & $37.1 \pm 15.5$ & $38.1 \pm 18.5$ & \\
\hline \multirow[t]{2}{*}{$\mathrm{S} 3+\mathrm{S} 4$} & $\%$ & $22.3 \pm 5.0$ & $19.9 \pm 7.0$ & $18.6 \pm 3.6$ & \\
\hline & $\min$ & $78.5 \pm 13.5$ & $71.3 \pm 19.1$ & $78.3 \pm 16.5$ & \\
\hline \multirow[t]{2}{*}{ REM } & $\%$ & $20.0 \pm 6.1$ & $18.7 \pm 5.9$ & $18.7 \pm 6.4$ & \\
\hline & $\min$ & $72.9 \pm 25.7$ & $71.1 \pm 27.4$ & $78.0 \pm 25.8$ & \\
\hline \multicolumn{2}{|c|}{ Movement time, min } & $1.1 \pm 1.3$ & $0.6 \pm 0.9$ & $1.4 \pm 1.4$ & $\mathrm{C}: \mathrm{P}^{*}$ \\
\hline \multicolumn{2}{|c|}{ REM latency, min } & $94.1 \pm 52.1$ & $80.4 \pm 29.8$ & $92.7 \pm 60.3$ & \\
\hline \multicolumn{2}{|c|}{ Stage shifts } & $122.2 \pm 37.7$ & $102.4 \pm 18.3$ & $103.1 \pm 25.3$ & \\
\hline
\end{tabular}

$\mathrm{A}=$ Predrug night; $\mathrm{P}=$ placebo night $\mathrm{C}=$ clonazepam $1 \mathrm{mg}$ night.

$* \mathrm{p}<0.05 ; * * \mathrm{p}<0.01$.

they demonstrated a longer latency to S4 and more frequent nocturnal awakenings in the first than in the second night (table 2). Acute administration of $1 \mathrm{mg}$ clonazepam shortened latency to S1 and S2, decreased wake within the TSP, and increased the TSP, TST and sleep efficiency (from 83 to $93 \%$ ) at the level of statistical significance.

\section{Objective Sleep Quality - Sleep Architecture}

Concerning S2, an adaptation phenomenon was observed as there was an increase in minutes spent in this stage from the predrug to the placebo night (table 3 ). Acute administration of $1 \mathrm{mg}$ clonazepam resulted in an increase in the percentage of S2 and movement time. 
Table 4. Bruxism index, respiratory variables and PLMs in sleep bruxers $(\mathrm{n}=10)$ : Acute effects of $1 \mathrm{mg}$ clonazepam and placebo

\begin{tabular}{|c|c|c|c|c|}
\hline Variables & $\begin{array}{l}\text { Normal } \\
\text { range }\end{array}$ & $\mathrm{P}$ & $\mathrm{C}$ & $\begin{array}{l}\text { Internight } \\
\text { differences } \\
\text { (Wilcoxon test) }\end{array}$ \\
\hline Bruxism index, $\mathrm{n} / \mathrm{h}$ of sleep & $0-4$ & $9.3 \pm 6.5$ & $6.3 \pm 3.4$ & $\mathrm{P}: \mathrm{C}^{* *}$ \\
\hline Apnea index, $\mathrm{n} / \mathrm{h}$ of sleep & $0-5$ & $0.3 \pm 0.6$ & $0.8 \pm 1.0$ & $\mathrm{P}: \mathrm{C}^{*}$ \\
\hline Apnea-hypopnea index, $\mathrm{n} / \mathrm{h}$ of sleep & $0-10$ & $0.9 \pm 1.0$ & $1.7 \pm 1.0$ & $\mathrm{P}: \mathrm{C}^{*}$ \\
\hline Desaturation index, $\mathrm{n} / \mathrm{h}$ of sleep & $0-5$ & $0.6 \pm 1.0$ & $1.9 \pm 2.0$ & \\
\hline Snoring index, $\mathrm{n} / \mathrm{h}$ of sleep & $0-20$ & $13.1 \pm 26.1$ & $16.3 \pm 17.4$ & \\
\hline PLMs, total n/TIB & & $181.6 \pm 140.1$ & $91.1 \pm 121.6$ & $\mathrm{P}: \mathrm{C}^{* *}$ \\
\hline PLM index, $\mathrm{n} / \mathrm{h}$ of TST & $0-5$ & $13.9 \pm 15.0$ & $8.9 \pm 5.1$ & $\mathrm{P}: \mathrm{C}^{*}$ \\
\hline PLM index awake, $\mathrm{n} / \mathrm{h}$ of time awake & & $67.6 \pm 35.9$ & $48.8 \pm 40.4$ & \\
\hline PLM-Arousal index, $\mathrm{n} / \mathrm{h}$ of sleep & $0-5$ & $2.7 \pm 3.2$ & $1.7 \pm 3.6$ & \\
\hline Arousal index total, $\mathrm{n} / \mathrm{h}$ of sleep & $0-20$ & $26.6 \pm 15.6$ & $24.7 \pm 16.0$ & \\
\hline
\end{tabular}

$\mathrm{P}=$ Placebo night $\mathrm{C}=$ clonazepam $1 \mathrm{mg}$ night. ${ }^{*} \mathrm{p}<0.05 ; * * \mathrm{p}<0.01$.

Table 5. Acute effects of $1 \mathrm{mg}$ clonazepam on subjective sleep/awakening quality and thymopsychic measures in sleep bruxers $(\mathrm{n}=10)$ as compared with placebo

\begin{tabular}{lcccc}
\hline Variables & A & P & C & $\begin{array}{l}\text { Internight } \\
\text { differences } \\
\text { (Wilcoxon test) }\end{array}$ \\
& & & & C:P** \\
Sleep quality, score $\downarrow$ & $15.2 \pm 4.4$ & $13.9 \pm 2.2$ & $9.5 \pm 4.1$ & \\
Awakening quality, score $\downarrow$ & $14.6 \pm 4.7$ & $16.2 \pm 4.9$ & $16.7 \pm 6.2$ & \\
Somatic complaints, score $\downarrow$ & $6.2 \pm 1.3$ & $6.0 \pm 1.2$ & $6.5 \pm 1.8$ & \\
SSA total, score $\downarrow$ & $36.0 \pm 8.8$ & $36.1 \pm 6.7$ & $32.7 \pm 10.9$ & \\
Well-being evening, score $\downarrow$ & $21.9 \pm 11.9$ & $17.6 \pm 11.0$ & $13.8 \pm 8.3$ & \\
Well-being morning, score $\downarrow$ & $14.6 \pm 10.2$ & $17.1 \pm 12.4$ & $16.3 \pm 10.7$ & \\
Drive, mm $\downarrow$ & $42.5 \pm 28.8$ & $47.9 \pm 30.1$ & $44.6 \pm 31.5$ & \\
Mood, mm $\uparrow$ & $72.4 \pm 15.8$ & $65.6 \pm 18.8$ & $58.1 \pm 26.0$ & \\
Affectivity, mm $\uparrow$ & $75.4 \pm 15.4$ & $67.5 \pm 25.5$ & $71.8 \pm 17.2$ & \\
Drowsiness, mm $\downarrow$ & $36.9 \pm 28.1$ & $50.4 \pm 28.5$ & $46.9 \pm 27.5$ & \\
\hline
\end{tabular}

A = Predrug night; $\mathrm{P}=$ placebo night; $\mathrm{C}=$ clonazepam $1 \mathrm{mg}$ night; SSA = Self-Assessment of Sleep and Awakening Quality Scale; $\downarrow \uparrow=$ direction of improvement. $* * \mathrm{p}<0.01$.

Objective Sleep Quality - Bruxism Index, Respiratory

\section{Variables and PLMs}

In accordance with the inclusion criteria, patients demonstrated an increased bruxism index of $9.3 \pm 6.5 / \mathrm{h}$ of sleep as compared with the normal rate of $0-4 / \mathrm{h}$ of sleep, with the active compound clonazepam $1 \mathrm{mg}$ improving the index significantly to $6.3 \pm 3.4$ (table 4 ).

The respiratory indices such as the apnea index, apnea-hypopnea index and desaturation index, as well as the snoring index were within normal limits and did not change significantly under clonazepam $1 \mathrm{mg}$ as compared with placebo (table 4).
PLMs during the total TIB, however, improved significantly under clonazepam as compared with placebo (table 4). With $13.9 \pm 15 / \mathrm{h}$, the PLM index was slightly elevated as compared with normative data $(0-5 / \mathrm{h})$ and improved significantly under clonazepam $1 \mathrm{mg}$ to $8.9 \pm$ 5.1/h. The PLM index during time awake decreased as well, but the decrease did not reach the level of statistical significance. The decrease in the arousal index and in the PLM-arousal index was not statistically significant either. 
Table 6. Acute effects of $1 \mathrm{mg}$ clonazepam on noopsychic performance in the morning in sleep bruxers $(\mathrm{n}=10)$ as compared with placebo

\begin{tabular}{lcccc}
\hline Variables & A & P & C & $\begin{array}{l}\text { Internight } \\
\text { differences } \\
\text { (Wilcoxon test) }\end{array}$ \\
\hline Attention, score $\uparrow$ & & & & \\
Concentration, \% errors $\downarrow$ & $520.8 \pm 77.6$ & $460.4 \pm 92.9$ & $494.3 \pm 94.2$ & A:P* \\
Attention variability, score $\downarrow$ & $3.3 \pm 1.9$ & $3.1 \pm 2.1$ & $3.6 \pm 2.4$ & \\
Numerical memory, $\uparrow$ & $14.6 \pm 3.7$ & $15.1 \pm 2.8$ & $14.0 \pm 4.3$ & \\
Fine motor activity (right) $\uparrow$ & $5.4 \pm 1.5$ & $4.4 \pm 1.8$ & $3.9 \pm 2.0$ & \\
Fine motor activity (left) $\uparrow$ & $34.1 \pm 8.4$ & $37.2 \pm 8.1$ & $37.6 \pm 5.6$ & \\
Fine motor activity (right + left) $\uparrow$ & $31.8 \pm 11.8$ & $36.4 \pm 7.7$ & $34.3 \pm 10.0$ & \\
Reaction time, ms $\downarrow$ & $63.9 \pm 19.5$ & $73.6 \pm 13.8$ & $71.9 \pm 14.1$ & A:P* \\
Reaction time variability, ms $\downarrow$ & $575.3 \pm 68.6$ & $602.8 \pm 78.2$ & $556.5 \pm 65.8$ & \\
Reaction time errors/commission $\downarrow$ & $139.3 \pm 40.5$ & $111.6 \pm 37.2$ & $111.9 \pm 50.2$ & \\
Reaction time errors/omission $\downarrow$ & $4.8 \pm 4.5$ & $2.2 \pm 3.2$ & $2.2 \pm 3.7$ & \\
\hline
\end{tabular}

$\mathrm{A}=$ Predrug night; $\mathrm{P}=$ placebo night; $\mathrm{C}=$ clonazepam $1 \mathrm{mg}$ night; $\uparrow \downarrow=$ direction of improvement.

$* \mathrm{p}<0.05 ; * * \mathrm{p}<0.01$.

\section{Subjective Sleep/Awakening Quality and}

\section{Thymopsychic Measures}

Subjective sleep quality, as rated by the patients themselves by means of the Self-Assessment of Sleep and Awakening Quality Scale, demonstrated a significant improvement after $1 \mathrm{mg}$ clonazepam as compared with placebo (table 5). There were no significant changes in the other subjective awakening quality and thymopsychic measures, nor were there any first-night effects in these variables in sleep bruxers.

\section{Objective Awakening Quality and Noopsychic}

\section{Measures}

Objective awakening quality variables on attention, concentration, numerical memory, fine motor activity and reaction time performance did not show any significant changes after clonazepam as compared with placebo (table 6). There was a first-night effect regarding fine motor activity measured in both hands, with better performance in the second than in the first night, whereas attention (measured by the Alphabetic Cancellation Test) was higher in the first than in the second night.

\section{Psychophysiological Measures}

Psychophysiological measures did not show any firstnight effect in sleep bruxers nor any significant changes after clonazepam as compared to placebo, with the exception of an improved muscular strength of the right finger (table 7).

\section{Discussion}

Our clinical investigations demonstrated that SB patients suffer from a disorder of initiating and maintaining sleep, which results in a slight increase in daytime sleepiness and a deterioration of quality of life. The slightly increased depression and anxiety symptomatology may be partly due to comorbidities including affective and anxiety disorders, which, however, in clinical psychiatry settings generally show much higher SAS and SDS scores. The same is true for the IRLSSG score, which is only mildly elevated in SB patients, but nevertheless substantiates the clinically diagnosed movement disorder. Further studies seem necessary to elucidate the relationship between SB and movement disorders. The increased anxiety and depression scores do speak for the decision to place SB in the F4 chapter on 'Neurotic, Stress-Related and Somatoform Disorders'. It is noteworthy that our studies in untreated RLS and periodic leg movement disorder (PLMD) patients also showed slightly elevated SAS and SDS scores, which at the neurophysiological level were accompanied by EEG maps resembling those found in depression and anxiety [76].

These subjectively experienced sleep disturbances were corroborated by objective polysomnographic data. After acute administration of $1 \mathrm{mg}$ clonazepam, a statistically significant improvement of subjective and objective sleep quality as well as a decrease in the bruxism index were observed. PLMs improved as well, which con- 
Table 7. Acute effects of $1 \mathrm{mg}$ clonazepam on psychophysiological measures in sleep bruxers $(\mathrm{n}=10)$ as compared with placebo

\begin{tabular}{|c|c|c|c|c|c|}
\hline Variables & & A & $\mathrm{P}$ & $\mathrm{C}$ & $\begin{array}{l}\text { Internight } \\
\text { differences } \\
\text { (Wilcoxon test) }\end{array}$ \\
\hline Vigorimeter & Right finger & $0.5 \pm 0.1$ & $0.4 \pm 0.1$ & $0.5 \pm 0.1$ & $\mathrm{C}: \mathrm{P}^{*}$ \\
\hline & Left finger & $0.4 \pm 0.1$ & $0.4 \pm 0.1$ & $0.4 \pm 0.1$ & \\
\hline & Right hand & $0.6 \pm 0.2$ & $1.1 \pm 1.3$ & $0.7 \pm 0.2$ & \\
\hline & Left hand & $0.6 \pm 0.2$ & $1.1 \pm 1.3$ & $0.6 \pm 0.2$ & \\
\hline \multicolumn{2}{|c|}{ Systolic blood pressure evening, mm Hg } & $117.0 \pm 14.6$ & $118.0 \pm 19.6$ & $120.0 \pm 24.8$ & \\
\hline \multicolumn{2}{|c|}{ Diastolic blood pressure evening, $\mathrm{mm} \mathrm{Hg}$} & $75.0 \pm 11.5$ & $73.5 \pm 11.6$ & $75.0 \pm 12.0$ & \\
\hline \multicolumn{2}{|c|}{ Pulse rate evening, bpm } & $62.2 \pm 9.1$ & $62.6 \pm 8.4$ & $63.1 \pm 8.6$ & \\
\hline \multicolumn{2}{|c|}{ Systolic blood pressure morning, $\mathrm{mm} \mathrm{Hg}$} & $120.6 \pm 11.8$ & $116.0 \pm 5.8$ & $121.4 \pm 17.2$ & \\
\hline \multicolumn{2}{|c|}{ Diastolic blood pressure morning, $\mathrm{mm} \mathrm{Hg}$} & $77.2 \pm 6.7$ & $74.5 \pm 8.0$ & $78.3 \pm 15.2$ & \\
\hline \multicolumn{2}{|c|}{ Pulse rate morning, bpm } & $63.2 \pm 10.5$ & $63.2 \pm 7.5$ & $63.9 \pm 11.4$ & \\
\hline
\end{tabular}

firms our previous studies in RLS and PLMD patients with the same compound [70]. Thymopsychic, noopsychic and psychophysiological variables showed no significant changes, which speaks for the good tolerability of the compound.

The improvement of the target variable - the bruxism index - is inasmuch of clinical interest as up to now pharmacological interventions have been inconclusive. Many years after a negative single-case report on $L$-dopa by Magee [77], Lobbezoo et al. [78] showed a modest (approximately $30 \%$ ) but significant reduction in SB-related motor activity. An increase in tooth grinding was reported by Micheli et al. [79] in schizophrenics treated with antidopaminergic drugs such as haloperidol. Recent controlled studies with the modest dopamine agonist bromocriptine did not reveal any effect on SB [72]. Utilizing propranolol, a $\beta$-adrenergic receptor blocker in an open study, Amir et al. [80] described a reduction of tooth grinding in patients treated with neuroleptics. On the other hand, one has to take into account that propranolol can both reduce sleep quality and worsen sleep disorders such as apnea, insomnia and REM behavior disorder [14]. The serotoninergic involvement in the pathophysiology of SB is also unclear. Serotonin reuptake inhibitors, such as fluoxetine, sertraline, fluvoxamine and paroxetine, have been associated with tooth clenching or tooth grinding [81-83]. On the other hand, the use of tryptophan, a 5-HT precursor, or a modest though classical serotonin reuptake-inhibiting drug, such as amitriptyline or its metabolites, failed to exacerbate or attenuate SB [84-86]. Recently, Huynh et al. [73] reported that clonidine, an $\alpha_{2}$ receptor agonist that causes central sym- pathetic nervous system depression, reduced the average sleep bruxism index and burst index by 61 and $73 \%$, respectively, after one dose of $0.3 \mathrm{mg}$ given at bedtime. However, as clonidine also caused a decrease in blood pressure upon awakening in 3 out of 16 subjects, this compound will not be implemented in clinical routine. Nevertheless, the findings confirm the hypothesis that SB is controlled centrally [87]. A further hindrance for clinical use of clonidine is the suppression of REM sleep from 20 down to $0 \%$. In our present study, clonazepam had no effect on sleep stages, except for a slight increase in the percentage of $\mathbf{S} 2$, which had already been described in our studies with clonazepam in RLS patients as well as PLMD patients [70]. The significant increase in the apnea and apnea-hypopnea index is a relative contraindication of the drug in sleep-related breathing disorders, but it has to be emphasized that both indices were changed only marginally and remained within normal limits.

Although our present acute drug trials with clonazepam seem very promising for the treatment of SB, further long-term studies are necessary in order to show the maintenance of therapeutic efficacy and long-term tolerability.

\section{Acknowledgements}

The authors would like to express their thanks to Mag. Elisabeth Grätzhofer for her valuable editorial assistance as well as to the entire staff of the Sleep Research and Pharmacopsychiatry Section of the Department of Psychiatry, Medical University of Vienna for their co-operative assistance in this project. 


\section{References}

1 Diagnostic Classification Steering Committee, Thorpy MJ, chairman: International Classification of Sleep Disorders: Diagnostic and Coding Manual, Revised. Rochester, American Sleep Disorders Association, 1997, pp 182185.

2 World Health Organisation: International Classification of Diseases and Related Health Problems. Geneva, World Health Organisation, 1992.

-3 Glaros AG, Rao SM: Bruxism: A critical review. Psychol Bull 1977;84:767-781.

4 Kristal L: Bruxism: An anxiety response to environmental stress; in Spielberger CD, Sarason IG (eds): Stress and Anxiety. Washington, Hemisphere, 1978, vol 5, pp 45-59.

5 Harness DM, Peltier B: Comparison of MMPI scores with self-report of sleep disturbance and bruxism in the facial pain population. Cranio 1992;10:70-74.

-6 Biondi M, Picardi A: Temporomandibular joint pain-dysfunction syndrome and bruxism: Etiopathogenesis and treatment from a psychosomatic integrative viewpoint. Psychother Psychosom 1993;59:84-98.

7 Hartmann E: Bruxism; in Kryger MH, Roth T, Dement WC (eds): Principles and Practice of Sleep Medicine. Philadelphia, WB Saunders Co, 1994, pp 598-604.

$\checkmark 8$ Kampe T, Tagdae T, Bader G, Edman G, Karlsson S: Reported symptoms and clinical findings in a group of subjects with longstanding bruxing behaviour. J Oral Rehabil 1997;24: 581-587.

-9 Pierce CJ, Chrisman K, Bennett ME, Close JM: Stress, anticipatory stress and psychologic measures related to sleep bruxism. J Orofac Pain 1995;9:51-56.

- 10 Pingitore G, Chrobak V, Petrie J: The social and psychologic factors of bruxism. J Prosthet Dent 1991;65:443-446.

-11 Bader GG, Kampe T, Tagdae T, Karlsson S, Blomqvist M: Descriptive physiological data on a sleep bruxism population. Sleep 1997;20: 982-990.

-12 Major M, Rompré PH, Guitard F, TenBokum L, O'Connors K, Nielsen TA, et al: A controlled daytime challenge of motor performance and vigilance in sleep bruxers. J Dent Res 1999;78:1754-1762.

13 Kato T, Thie N, Montplaisir J, Lavigne GJ: Bruxism and orofacial movements during sleep. Dent Clin North Am 2001;45:657684.

14 Lavigne GJ, Manzini C: Sleep bruxism and concomitant motor activity; in Kryger $\mathrm{MH}$, Roth T, Dement WC (eds): Principles and Practice of Sleep Medicine. Philadelphia, WB Saunders Co, 2000, pp 773-785.

15 Macaluso GM, Guerra P, Di Giovanni G, Boselli M, Parrino L, Terzano MG: Sleep bruxism is a disorder related to periodic arousals during sleep. J Dent Res 1998;77:565-573.
16 Kato T, Rompré PH, Montplaisir JY, Sessle BJ, Lavigne GJ: Sleep bruxism: An oromotor activity secondary to microarousal. J Dent Res 2001;80:1940-1944.

17 Reding GR, Rubright WC, Zimmermann SO: Incidence of bruxism. J Dent Res 1966;45: 1198-1204.

18 Glaros AG: Incidence of diurnal and nocturnal bruxism. J Prosthet Dent 1981;45:545-549.

19 Lavigne GJ, Montplaisir J: Restless legs syndrome and sleep bruxism: Prevalence and association among Canadians. Sleep 1994;17: 739-743.

20 Ohayon MM, Li KK, Guilleminault C: Risk factors for sleep bruxism in the general population. Chest 2001;119:53-61.

21 Laberge L, Tremblay RE, Vitaro F, Montplaisir J: Development of parasomnias from childhood to early adolescence. Pediatrics 2000; 106:67-74.

22 Bader G, Lavigne GJ: Sleep bruxism: Overview of an oromandibular sleep movement disorder. Sleep Med Rev 2000;4:27-43.

23 Johansson A, Haraldson T, Omar R, Kiliaridis S, Carlsson GE: A system for assessing the severity and progression of occlusal wear. J Oral Rehabil 1993;20:125-131.

24 Lavigne GJ, Rompré PH, Montplaisir J: Sleep bruxism: Validity of clinical research diagnostic criteria in a controlled polysomnographic study. J Dent Res 1996;75:546-552.

25 Kato T, Montplaisir J, Blanchet P, Lund JP, Lavigne GJ: Idiopathic myoclonus in the oromandibular region during sleep: A possible source of confusion in sleep bruxism diagnosis. Mov Disord 1999;14:865-871.

-26 Lavigne GJ, Rompré PH, Poirier G, Huard H, Kato T, Montplaisir JY: Rhythmic masticatory muscle activity during sleep in humans. $\mathrm{J}$ Dent Res 2001;80:443-448.

27 Halasz P, Ujszaszi J, Gadoros J: Are microarousals preceded by electroencephalographic slow wave synchronization precursors of confusional awakenings? Sleep 1985;8:231-238.

28 Saletu B, Saletu-Zyhlarz GM: Was Sie schon immer über Schlaf wissen wollten. Wien, Ueberreuter, 2001.

29 Pierce CJ, Gale EN: A comparison on different treatments for nocturnal bruxism. J Dent Res 1988;67:597-601.

30 Moss RA, Hammer D, Adams HE, Jenkins JO, Thompson K, Haber J: A more efficient biofeedback procedure for the treatment of nocturnal bruxism. J Oral Rehabil 1982;9:125131.

31 Clarke JH, Reynolds PJ: Suggestive hypnotherapy for nocturnal bruxism: A pilot study. Am J Clin Hypn 1991;33:248-253.

32 Hudzinski LG, Walters PJ: Use of a portable electromyogram integrator and biofeedback unit in the treatment of chronic nocturnal bruxism. J Prosthet Dent 1987;58:698-701.

33 Rugh JD, Johnson RW: Temporal analysis of nocturnal bruxism during EMG feedback. J Periodontol 1981;52:263-265.
34 Solberg WK, Clark GT, Rugh JD: Nocturnal electromyographic evaluation of bruxism patients undergoing short term splint therapy. J Oral Rehabil 1975;2:215-223.

35 Clark GT, Beemsterboer PL, Solberg WK, Rugh JD: Nocturnal electromygraphic evaluation of myofascial pain dysfunction in patients undergoing occlusal splint therapy. J Am Dent Assoc 1979;99:607-611.

36 Okeson JP: The effects of hard and soft occlusal splints on nocturnal bruxism. J Am Dent Assoc 1987;114:788-791.

- 37 Holmgren K, Sheikholeslam A, Riise C: Effect of a full-arch maxillary occlusal splint on parafunctional activity during sleep in patients with nocturnal bruxism and signs and symptoms of craniomandibular disorders. J Prosthet Dent 1993;69:293-297.

38 Macaluso GM, Conversi G, Guerra P, Smerieri A, Boselli M, Parrino L, et al: Effect of splint therapy on sleep structure in bruxers. J Dent Res 1998;77:920.

- 39 Dao TTT, Lavigne GJ: Oral splints: The crutches for temporomandibular disorders and bruxism? Crit Rev Oral Biol Med 1998;9:345361.

40 Yustin D, Neff P, Rieger MR, et al: Characterization of 86 bruxing patients and long term study of their management with occlusal devices and other forms of therapy. J Orofac Pain 1993; 7:54-60.

41 Ramfjord SP, Mich AA: Bruxism: A clinical and electromyographic study. J Am Dent Assoc 1961;62:35-58.

42 Clark GT, Adler C: A critical evaluation of occlusal therapy: Occlusal adjustment procedures. J Am Dent Assoc 1985;110:743-750.

43 Okeson JP: Orofacial Pain Guidelines for Assessment, Diagnosis, and Management. Carol Stream, Quintessence, 1996.

44 Lavigne GJ, Montplaisir J: Bruxism: Epidemiology, diagnosis, pathophysiology, and pharmacology; in Friction JR, Dubner RB (eds): Advances in Pain Research and Therapy Orofacial Pain and Temporomandibular Disorders. New York, Raven Press, 1995, pp 387 404.

45 Dube C, Rompré PH, Manzini C, Guitard F, de Grandmont P, Lavigne GJ: Quantitative polygraphic controlled study on efficacy and safety of oral splint devices in tooth-grinding subjects. J Dent Res 2004;83:398-403.

46 Oksenberg A, Arons E: Sleep bruxism related to obstructive sleep apnea: The effect of continous positive airway pressure. Sleep Med 2002;3513-515.

-47 Winocur E, Gavish A, Voikovitch M, EmodiPerlman A, Eli I: Drugs and bruxism: A critical review. J Orofac Pain 2003;17:99-111.

48 Hauer C, Saletu-Zyhlarz G, Mandl M, Saletu M, Piehslinger E, Saletu: Bruxismus-Diagnose und Therapie. Presented at the 41 Fachtagung für Neurophysiologie und angrenzende Gebiete, Champfer, Switzerland, 2002. 
-49 Buysse DJ, Reynolds CF 3rd, Monk TH, Berman SR, Kupfer DJ: The Pittsburgh Sleep Quality Index: A new instrument for psychiatric practice and research. Psychiatry Res 1989; 28:193-213.

-50 Zung W: A self-rating depression scale. Arch Gen Psychiatry 1965;12:63-70.

51 Zung W: SAS, Self-Rating Anxiety Scale; in Guy W (ed): ECDEU Assessment Manual for Psychopharmacology. Rockville, US National Institute of Health, 1976, pp 337-340.

$\checkmark 52$ Johns MW: A new method for measuring daytime sleepiness: The Epworth Sleepiness Scale. Sleep 1991; 14:540-545.

$\checkmark 53$ Walters AS, LeBrocq C, Dhar A, Hening W, Rosen R, Allen RP, Trenkwalder C: Validation of the International Restless Legs Syndrome Study Group rating scale for restless legs syndrome. Sleep Med 2003;4:121-132.

\$5 Mezzich JE, Ruiperez MA, Perez C, Yoon G, Liu J, Mahmud S: The Spanish version of the quality of life index: Presentation and validation. J Nerv Ment Dis 2000;188:301-305.

-55 Saletu B, Prause W, Löffler-Stastka H, Anderer P, Brandstätter N, Zoghlami A, Saletu-Zyhlarz G, Katschnig H: Quality of life in nonorganic and organic sleep disorders. 1. Comparison with normative data. Wien Klin Wochenschr 2003; 115:246-254.

$\checkmark 56$ Prause W, Saletu B, Anderer P, Gruber G, Löffler-Stastka H, Klösch G, Mandl M, Grätzhofer E, Saletu-Zyhlarz G, Katschnig H: Quality of life in nonorganic and organic sleep disorders. 2. Correlation with objective and subjective quality of sleep and awakening. Wien Klin Wochenschr 2003;115: 326-333.

57 Sleep Disorders Atlas Task Force of the American Sleep Disorders Association: Recording and scoring leg movements. Sleep 1993;16: 749-759.

58 Sleep Disorders Atlas Task Force of the American Sleep Disorders Association: EEG arousals: Scoring rules and examples: A preliminary report from the Sleep Disorders Atlas Task Force of the American Sleep Disorders Association. Sleep 1992;15:173-184.

59 Rechtschaffen A, Kales A: A Manual of Standardized Terminology, Technique and Scoring System for Sleep Stages of Human Subjects. Los Angeles, University of California Brain Information Service, 1968.

60 Saletu B, Wessely P, Grünberger J, Schultes M: Erste klinische Erfahrungen mit einem neuen schlafanstossenden Benzodiazepin, Cinolazepam, mittels eines Selbstbeurteilungsbogens für Schlaf- und Aufwachqualität (SSA). Neuropsychiatrie 1987;1:169-176.

61 Saletu B, Anderer P, Frey R, Krupka M, Klösch G: Zur Neurophysiologie des Schlafes. Psychiatr Danub 1991;3:31-58.
62 Von Zerssen D, Koeller DM, Rey ER: Die Befindlichkeits-Skala (Bf-S) - Ein einfaches Instrument zur Objektivierung von Befindlichkeits-Störungen, insbesondere im Rahmen von Längsschnittuntersuchungen. Arzneimittelforschung 1970;20:915-918.

63 Grünberger J: Psychodiagnostik des Alkoholkranken. Ein methodischer Beitrag zur Bestimmung der Organizität in der Psychiatrie. Wien, Maudrich, 1977.

64 Fünfgeld EW: Vigorimeter: Zur Kraftmessung der Hand und zur Simulationsprüfung. Dscht Med Wochenschr 1966;49:2214-2216.

65 Benca RM, Obermeyer WH, Thisted RA, Gillin JC: Sleep and psychiatric disorders: A metaanalysis. Arch Gen Psychiatry 1992;49:651668.

66 Saletu-Zyhlarz GM, Abu-Bakr MH, Anderer P, Semler B, Decker K, Parapatics S, Tschida U, Winkler A, Saletu B: Insomnia related to dysthymia: Comparison with normal controls and acute therapeutic trials with trazodone. Neuropsychobiology 2001;44:139-149.

67 Saletu-Zyhlarz GM, Hassan Abu-Bakr M, Anderer P, Gruber G, Mandl M, Strobl R, Gollner D, Prause W, Saletu B: Insomnia in depression: Differences in objective and subjective sleep and awakening quality to normal controls and acute effects of trazodone. Prog Neuropsychopharmacol Biol Psychiatry 2002;26:249_ 260.

68 Saletu M, Anderer P, Saletu B, Hauer C, Mandl M, Oberndorfer S, Zoghlami A, Saletu-Zyhlarz G: Sleep laboratory studies in restless legs syndrome patients as compared with normals and acute effects of ropinirole. 2. Findings on periodic leg movements, arousals and respiratory variables. Neuropsychobiology 2000;41:190199.

69 Saletu M, Anderer P, Saletu B, Hauer C, Mandl M, Semler B, Saletu-Zyhlarz G: Sleep laboratory studies in periodic limb movement disorder (PLMD) as compared with normals and acute effects of ropinirole. Hum Psychopharmacol 2001;16:177-187.

70 Saletu M, Anderer P, Saletu-Zyhlarz G, Prause W, Semler B, Zoghlami A, Gruber G, Hauer C, Saletu B: Restless legs syndrome (RLS) and periodic limb movement disorder (PLMD). Acute placebo-controlled sleep laboratory studies with clonazepam. Eur Neuropsychopharmacol 2001;11:153-161.

71 Saletu B, Gruber G, Saletu M, Brandstätter N, Hauer C, Prause W, Ritter K, Saletu-Zyhlarz G: Sleep laboratory studies in restless legs syndrome patients as compared with normals and acute effects of ropinirole. 1. Findings on objective and subjective sleep and awakening quality. Neuropsychobiology 2000;41:181189.

72 Lavigne GJ, Soucy J-P, Lobbezoo F, Manzini C, Blanchet PJ, Montplaisir JY: Double blind crossover, placebo-controlled trial with bromocriptine in patients with sleep bruxism. Clin Neuropharmacol 2001;4:145-149.
73 Huynh NT, Lavigne GJ, Guitard F, Rompre PH, de Chaplain J, Montplaisir JY: Clonidine reduces sleep bruxism activity in a doubleblind randomized crossover trial: Preliminary findings. 17th Congr Eur Sleep Res Soc, Prague, 2004.

74 Abt K: Descriptive data analysis (DDA) in quantitative EEG studies; in Samson-Dollfus D, Guieu JD, Gotman J, Etevenon P (eds): Statistics and Topography in Quantitative EEG. Amsterdam, Elsevier, 1988, pp 150-160.

75 Ferber G, Abt K, Fichte K, Luthringer R: IPEG guideline on statistical design and analysis for pharmacodynamic trials. Neuropsychobiology 1999;39:92-100.

76 Saletu B, Anderer P, Saletu M, Hauer C, Lindeck-Pozza L, Saletu-Zyhlarz G: EEG mapping, psychometric, and polysomnographic studies in restless legs syndrome (RLS) and periodic limb movement disorder (PLMD) patients as compared with normal controls. Sleep Med 2002;3(suppl 1):S35-S42.

77 Magee KR: Bruxism related to levodopa therapy. J Am Dent Assoc 1970;214:147.

78 Lobbezoo F, Lavigne GJ, Tanguay R, et al: The effect of catecholamine precursor $L$-dopa on sleep bruxism: A controlled clinical trial. Mov Disord 1997; 12:73-78.

79 Micheli F, Pardal MF, Gatto M, et al: Bruxism secondary to chronic antidopaminergic drug exposure. Clin Neuropharmacol 1993;16:315323.

80 Amir I, Hermesh H, Gavish A: Bruxism secondary to antipsychotic drug exposure: A positive response to propanolol. Clin Neuropharmacol 1997;20:86-89.

81 Ellison JA, Stanziani P: SSRI-associated nocturnal bruxism in four patients. J Clin Psychiatry $1993 ; 54: 432-434$.

82 Por CH, Watson L, Doucette D, et al: Sertraline-associated bruxism. Can J Clin Pharmacol 1996;3:123-125.

83 Gerber PE, Lynd LD: Selective serotoninreuptake inhibitor-induced movement disorders. Ann Pharmacother 1998;32:692-698.

84 Etzel KR, Stockstill JW, Rugh JD, et al: Tryptophan supplementation for nocturnal bruxism. Report of negative results. J Craniomandib Disord 1991;5:115-119.

85 Mohamed SE, Christensen LV, Penchas J: A randomized double-blind clinical trial of the effect of amitriptyline on nocturnal masseteric motor activity (sleep bruxism). Cranio 1997; 15:326-332.

86 Raigrodski A, Christensen L, Mohamed S, Gardiner D: The effect of a 4-week administration of amitriptylin on sleep bruxism. A double-blind crossover clinical study. Cranio 2001; 19:21-25.

87 Lobbezoo F, Naeije M: Bruxism is mainly regulated centrally, not peripherally. J Oral Rehabil 2001;12:1085-1091. 